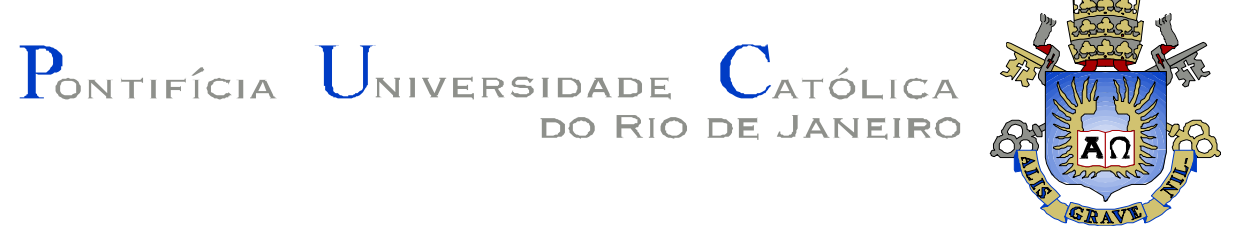

Renata Granchi Steidel de Toledo

\title{
O DISCURSO DA INTERATIVIDADE NA TELEVISÃO BRASILEIRA
}

Dissertação apresentada como requisito parcial para obtenção do grau de mestre pelo Programa de Pós-graduação em Psicologia Clínica do Departamento de Psicologia da PUC-Rio.

Orientadora: Prof. Ana Maria Nicolaci-da-Costa 


\section{Renata Granchi Steidel de Toledo}

\section{"O discurso da interatividade na televisão brasileira"}

Dissertação apresentada como requisito parcial para obtenção do grau de Mestre pelo Programa de Pós-Graduação em Psicologia Clínica do Departamento de Psicologia do Centro de Teologia e Ciências Humanas da PUC-Rio. Aprovada pela Comissão Examinadora abaixo assinada.

Profa Ana Maria Nicolaci-da-Costa

Orientadora

Departamento de Psicologia - PUC-Rio

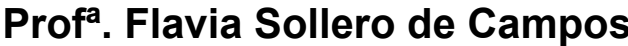
Departamento de Psicologia - PUC-Rio

Prof. Marcio Souza Gonçalves Departamento de Teoria da Comunicação -UERJ

Prof. Paulo Fernando Carneiro de Andrade Coordenador Setorial de Pós-Graduação e Pesquisa do Centro de Teologia e Ciências Humanas - PUC-Rio

Rio de Janeiro, 05 de fevereiro de 2004 
Todos os direitos reservados. É proibida a reprodução total ou parcial do trabalho sem autorização do autor, do orientador e da universidade.

\section{Renata Granchi Steidel de Toledo}

Jornalista, graduada em Comunicação Social pela Pontifícia Universidade Católica do Rio de Janeiro (PUC-Rio), no ano de 1996, com atuação nas áreas de pesquisa, produção, redação e edição em diversos meios de comunicação, principalmente em internet e televisão.

\section{Ficha catalográfica}

Toledo, Renata Granchi Steidel de

O discurso da interatividade na televisão brasileira / Renata Granchi Steidel de Toledo ; orientadora: Ana Maria Nicolaci-da-Costa. - Rio de Janeiro : PUC-Rio, Departamento de Psicologia, 2004.

97 f. : il. ; $30 \mathrm{~cm}$

Dissertação (mestrado) - Pontifícia Universidade Católica do Rio de Janeiro, Departamento de Psicologia.

Inclui referências bibliográficas

1. Psicologia - Teses. 2. Subjetividade. 3. Televisão. 4. Telespectador. 5. Internet. 6. Interatividade. 7. Multimídia. I. Nicolaci-da-Costa, Ana Maria. II. Pontifícia Universidade Católica do Rio de Janeiro. Departamento de Psicologia. III. Título. 
A minha mãe, que me ensinou a ser persistente $e$ não ter medo de desafios.

A meu irmão, por ter me ensinado a raciocinar e pensar analiticamente. 


\section{Agradecimentos}

À PUC-Rio por ter financiado a minha pesquisa.

À Ana, por ter acreditado em mim. Sem seu apoio e orientação eu jamais conseguiria. Com você aprendi que a simplicidade do raciocínio é, muitas vezes, o melhor caminho a se seguir.

Dedico um especial agradecimento aos professores que me ajudaram a dar os primeiros passos na psicologia: Zé Mauro e Flávia Sollero. Obrigada aos dois. Sem vocês eu também não teria conseguido.

À família Medeiros, que sempre me incentivou a estudar.

Ao CEDOC - Centro de Documentação da Rede Globo de Televisão -, mas em especial a Rita Marques, Laura Martins, Rachel Kudlowiez, Ana Cristina Borges e Maria Alice Fontes.

À Carla, Rico, Thereza, Rosane, Dani, Érika e a todos os meus colegas de mestrado e doutorado do grupo de estudo da Ana. Várias vezes me ajudaram com dicas, conselhos e orientações. Sem vocês teria sido impossível concluir este trabalho.

Às secretárias do departamento, sempre eficientes e atenciosas.

Aos professores da pós-graduação. Todos grandes mestres.

À Elisa e Rafaella. Minhas duas grandes amigas. Nem todo mundo entende que as noites de sexta e de sábado também podem ser usadas para estudar. Vocês entenderam. Obrigada. Vocês são demais!

À minha avó Ida, sempre preocupada com a minha alimentação. 
Ao meu pai, que me mostrou o mundo da comunicação.

A minha avó Irene. A primeira grande pesquisadora que conheci e que me mostrou a importância de ser organizada.

Após dois anos de intenso estudo, e muitos finais de semana entre papéis e livros, devo especial agradecimento ao meu computador. Com certeza sem ele nada disso seria possível.

Aos meus gatos, Micro e Copérnico e ao meu cachorro, Zeca. Sempre felizes!

À Benirá, pelo companheirismo e ajuda.

Ao meu marido, maior de todos os companheiros, que ficou várias madrugadas ao meu lado levando sanduíche, segurando o cachorro, atendendo telefone e lendo os meus textos. Ele, que nunca reclamou de ficar em casa para eu poder estudar, o meu especial agradecimento e amor. 


\section{Resumo}

\section{O discurso da interatividade na televisão brasileira}

O surgimento e a popularização de meios de comunicação interativos, como a Internet, fizeram com que o discurso da interatividade se difundisse e fosse absorvido pelas emissoras de televisão ao redor do mundo. A presente dissertação tinha como objetivo investigar de que forma os telespectadores estão percebendo o uso desse discurso na televisão brasileira. Primeiramente, nele são analisadas: (a) a relação entre a televisão e o telespectador, (b) a difusão da palavra interatividade, (c) os principais programas que vêm utilizando este discurso e, finalmente, (d) os conceitos de multimídia e convergência. Posteriormente, são apresentados os resultados de 10 entrevistas face-a-face realizadas com homens e mulheres brasileiros, telespectadores típicos e usuários da Internet. A análise do discurso desses entrevistados revelou a existência de dois tipos distintos de telespectadores: os potencialmente interativos e os não interativos. Ambos não percebem a TV como um meio de comunicação interativo. Para eles, o discurso da interatividade está vinculado a um novo estilo de programa que a TV vem divulgando.

\section{Palavras-chave}

Subjetividade, televisão, internet, interatividade, multimídia. 


\section{Abstract}

\section{The discourse of interactivity in Brazilian television}

The advent and popularization of interactive communications media, such as the internet, led to the dissemination of the discourse of interactivity. Such a discourse was absorbed by television broadcasters worldwide. The present dissertation had the goal of investigating how television viewers perceive the use of this discourse in Brazilian television. Primarily, the following are analyzed: (a) the relationship between television and television viewer; (b) the diffusion of the word "interactivity"; (c) the main TV shows that have been utilizing this discourse and, finally, (d) the concepts of multimedia and convergence. Lastly, the results of 10 face-to-face interviews with typical Brazilian male and female television viewers, who are also internet users, are presented. The analysis of the interviewees' replies revealed the existence of two distinct types of television viewers: the potentially interactive and the non-interactive ones. Both do not perceive the $\mathrm{TV}$ as an interactive communications medium. For them the discourse of Interactivity is associated with a new style of television shows that broadcasters are promoting.

\section{Keywords}

Subjectivity, television, Internet, interactivity, multimedia. 


\section{Sumário}

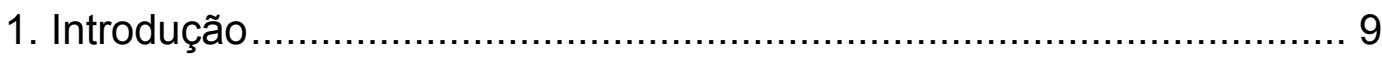

2. A TV na era da interatividade. O início de um novo discurso............... 12

2.1. Televidere, ou a TV propriamente dita.......................................... 12

2.1.1. Um breve histórico da televisão no Brasil. Do nascimento ao

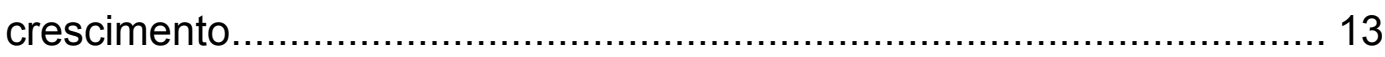

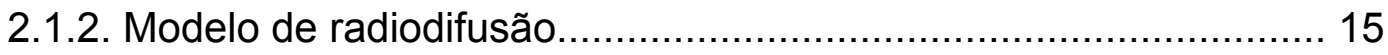

2.1.3. Relação do telespectador com a televisão................................... 16

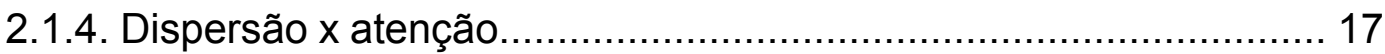

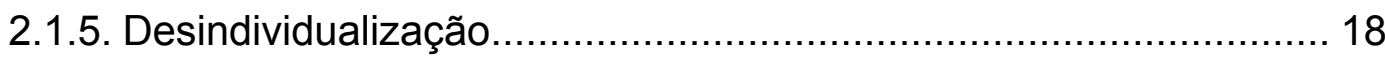

2.1.5.1. TV Fechada, a busca da individualização................................. 18

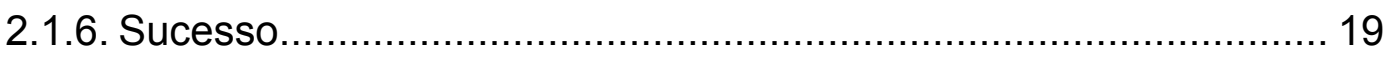

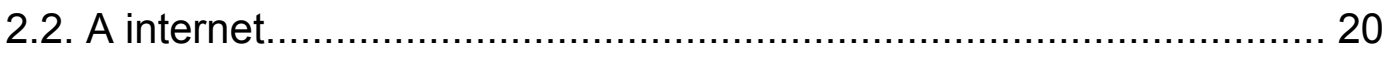

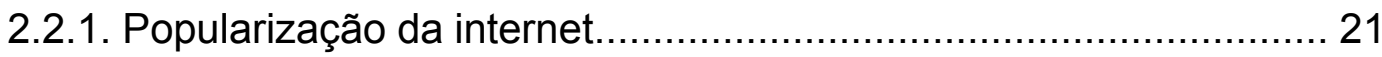

2.2.2. Relação do usuário com a internet............................................ 23

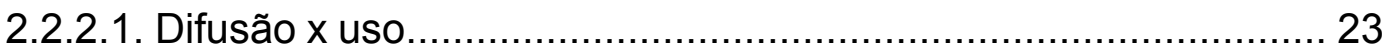

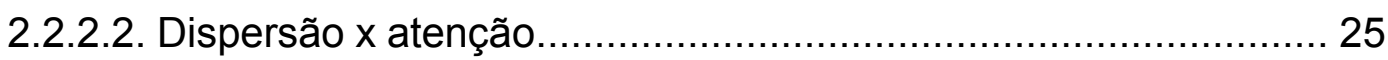

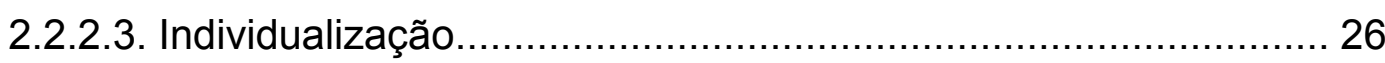

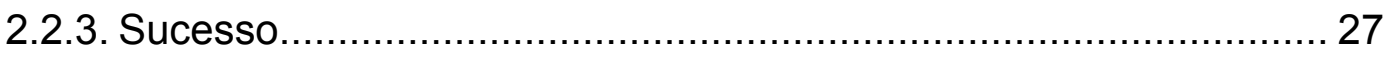

2.2.4. Modelo de transito de informações ou a interatividade propriamente

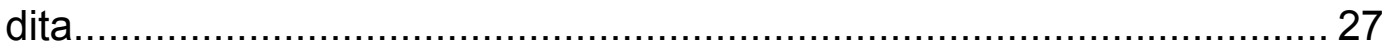

2.3. Programas interativos ou interatividade nos programas?................. 28

2.3.1. O discurso da interatividade usado pelas emissoras de TV........... 29

2.3.2. O discurso da interatividade, um objeto de estudo?..................... 33

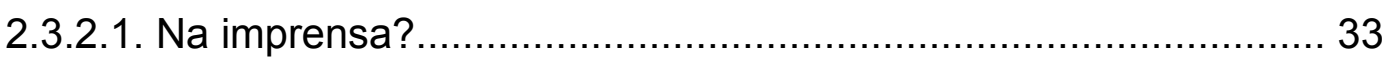

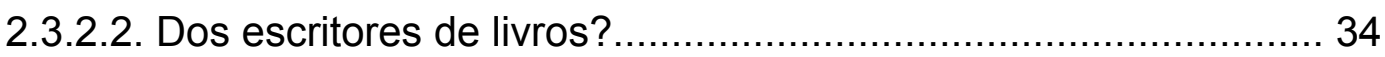

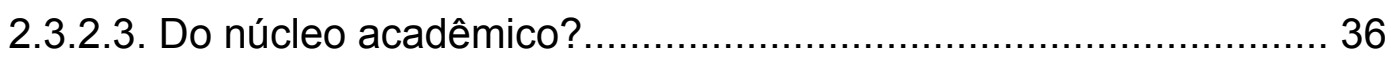

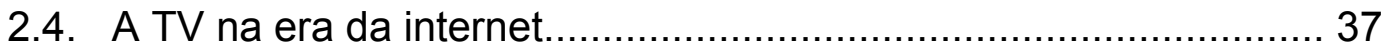

2.4.1 Multimídia, unimídia ou convergência?....................................... 39

2.4.1.1. Unimídia e convergência. Uma questão de nomenclatura.......... 41 
3. Investigando o discurso da interatividade da televisão $x$ telespectador 45

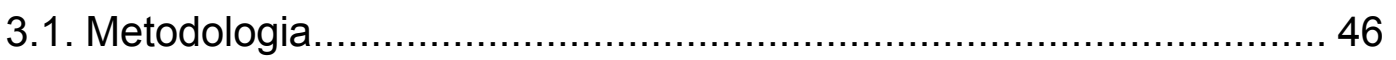

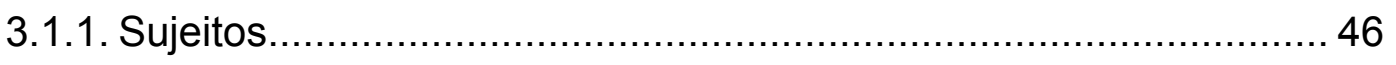

3.1.2. Coleta de material............................................................. 47

3.1.3. Depoimentos coletados.................................................. 48

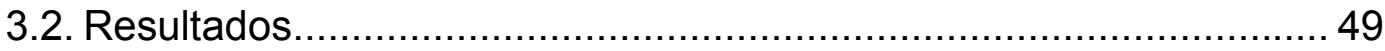

3.2.1. Hábitos ao assistir televisão................................................ 49

3.2.2. Programas preferidos..................................................... 50

3.2.3. Participação do telespectador nos programas........................... 53

3.2.4. Formas de acesso aos programas de TV .............................. 58

3.2.5. Avaliação dos programas de TV que utilizam o discurso da

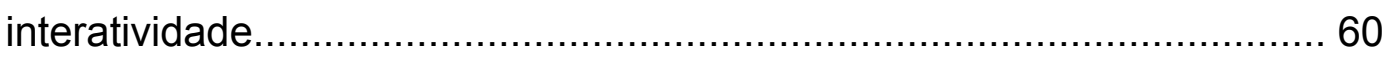

3.2.6. O que os programas devem fazer para o telespectador querer

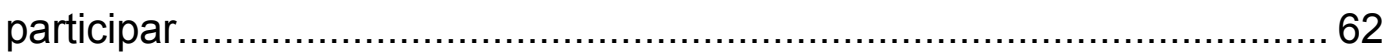

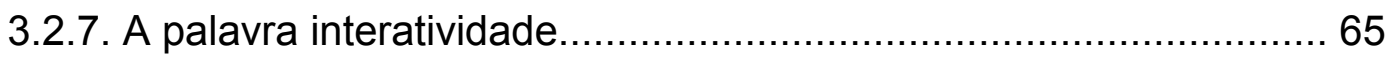

3.2.8. Significado da palavra interatividade..................................... 66

3.2.9. Percepção do uso do discurso da interatividade da TV................68 68

4. Retomando os resultados à luz do que é dito sobre interatividade...... 73

4.1. Audiência ou telespectadores potencialmente interativos................ 76

4.2. Telespectadores não interativos......................................... 79

4.3. Os discursos semelhantes dos telespectadores potencialmente interativos e não interativos...................................................... 81

4.4. Afinal, o telespectador percebe a TV como interativa? O discurso da interatividade à luz do que foi dito pelos entrevistados........................ 85

5. Referências bibliográficas...................................................... 91

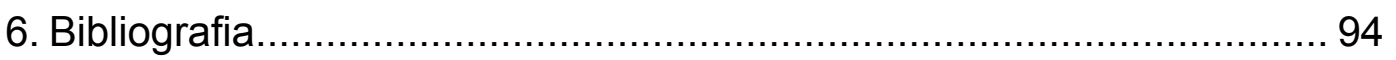

